\title{
Rationale of anticoagulation among patients of COVID-19 undergoing cardiac surgery
}

\author{
Dhruva Sharma ${ }^{1}$ (D) \\ Received: 12 June 2020 / Accepted: 17 June 2020 /Published online: 21 July 2020 \\ (C) Indian Association of Cardiovascular-Thoracic Surgeons 2020
}

\section{To the Editor:}

Since December 2019, there has been substantial spurt in the cases of coronavirus disease 2019 (COVID-19). Of late it was chronicled that $20 \%$ of COVID-19 patients had coagulation abnormalities. This coagulopathy among COVID-19 patients is responsible for increased incidences of morbidity and mortality $[1,2]$. Moreover, autopsy studies have also registered evidence of macro as well as micro embolism in patients with COVID-19 infection [3].

Tang et al. delineated in their study among 449 severe COVID-19 patients that the 28-day mortality of heparin users (99 patients) was lower than nonusers in patients with sepsisinduced coagulopathy score $\geq 4$ ( $40.0 \%$ vs $64.2 \%, p=.029)$, or D-dimer $>6$-fold of upper limit of normal $(32.8 \%$ vs $52.4 \%, p=.017$ ), although no difference in 28-day mortality was found between heparin users and nonusers $(30.3 \%$ vs $29.7 \%, p=.910)$. Yet, D-dimer, prothrombin time, and age were found to be positively correlated with 28-day mortality in multivariate analysis [2].

Significant elevation of D-dimer and fibrinogen degradation products (FDP) was seen among COVID19-related deaths. Even so, this diagnosis should be confirmed by imaging $[4,5]$.

However, Tremblay et al. performed a propensity-matched analysis of patients who were on empiric antithrombotic therapy prior to COVID-19 infection which was compared with those who were on neither anticoagulant nor antiplatelet therapy. They found that there was no statistically significant difference in survival $(p=.367)$ and time to mechanical ventilation $(p=.742)$ between the two groups. These results are suggestive of the fact that empiric antithrombotic prophylaxis

Dhruva Sharma

drsharmadhruva1981@gmail.com

1 Department of Cardiothoracic and Vascular Surgery, SMS Medical College \& Attached group of Hospitals, Jaipur, India alone is unlikely to be protective for morbidity and mortality due to COVID-19. They emphasized that more prospective randomized controlled trials should be promoted to validate these findings [6].

In the current times when we are about to restart our elective cardiovascular thoracic surgical procedures and knowing that COVID-19 is significantly associated with abnormalities of coagulation axis, the author wants Indian Association of Cardiothoracic and Vascular Surgeons through the editor to come out with strict recommendation and guidelines regarding "Do's and Dont's" of surgical procedures for the next 6 months to 1 year till the time vaccine is available or adequate herd immunity develops. Nonetheless, after surgical procedure the patient will be discharged and will be sent back to community where he may develop asymptomatic as well as symptomatic COVID-19 infection, which may affect coagulation cascades of the body which might result in increased incidence of thrombosis associated with biprosthetic grafts, mechanical prosthetic valves, etc. Strict guidelines should be drafted regarding which procedure should be done. The author is of thought that the procedures which are non-urgent should be avoided and the patient can be safely kept on prophylactic pharmacological management unless contraindicated till further course of disease is clear.

Repeated assessment of thrombotic risk and optimized pharmacological and surgical strategies are the need of the hour to prevent venous thromboembolism and pulmonary embolism. It should also be clarified which subset of COVID-19 patients should specifically be given empiric anti-thrombotic therapy.

Funding No funding was required for this article.

\section{Compliance with ethical standards}

Conflict of interest The author declares that he has no conflicts of interest. 
Ethical approval Not applicable.

\section{References}

1. Chen N, Zhou M, Dong X, et al. Epidemiological and clinical characteristics of 99 cases of 2019 novel coronavirus pneumonia in Wuhan, China: a descriptive study. Lancet. 2020;395:507-13.

2. Tang N, Li D, Wang X, Sun Z. Abnormal coagulation parameters are associated with poor prognosis in patients with novel coronavirus pneumonia. J Thromb Haemost. 2020;18:844-7.

3. Wichmann D, Sperhake JP, Lütgehetmann M, et al. Autopsy findings and venous thromboembolism in patients with COVID-19: a prospective cohort study. Ann Intern Med. Ann Intern Med. 2020. https://doi.org/10.7326/M20-2003.
4. Levi M, Thachil J, Iba T, Levy JH. Coagulation abnormalities and thrombosis in patients with COVID-19. Lancet Haematol. 2020;7: E438-40.

5. Lax SF, Skok K, Zechner P, et al. Pulmonary arterial thrombosis in COVID-19 with fatal outcome: results from a prospective, singlecenter, clinicopathologic case series. Ann Intern Med. 2020. https:// doi.org/10.7326/M20-2566.

6. Tremblay D, van Gerwen $M$, Alsen $M$, et al. Impact of anticoagulation prior to COVID-19 infection: a propensity scorematched cohort study. Blood. 2020. https://doi.org/10.1182/blood. 2020006941.

Publisher's note Springer Nature remains neutral with regard to jurisdictional claims in published maps and institutional affiliations. 